\title{
KETEPATAN POWER REFRAKTIF MATA ANTARA HASIL RETINOSKOP DENGAN TENTATIF KOREKSI SEBAGAI ACUAN REFRAKSI SUBJEKTIF
}

\author{
Anggit Nugroho ${ }^{1}$, Aang Anwarudin ${ }^{2)}$ \\ ${ }^{1,2)}$ Program Studi Diploma Tiga Refraksi Optisi STIKes Dharma Husada Bandung \\ anggit.ro@gmail.com
}

\begin{abstract}
ABSTRAK
Penyelenggaraan upaya kesehatan untuk mencapai hidup sehat bagi setiap penduduk bertujuan untuk mewujudkan derajat kesehatan yang optimal bagi pengembangan dan pembinaan sumber daya manusia sebagai modal pembangunan nasional. Untuk menunjang upaya tersebut, seorang refraksi optisi harus memiliki kompetensi untuk dapat melakukan pemeriksaan refraksi subjektif monokular dan menetapkan kelainan refraksi dan jenis terapi yang diperlukan. Mencari kesesuaian metode pemeriksaan mata antara hasil retinoskopi dengan tentatif koreksi untuk memudahkan dalam pemeriksaan refraksi subjektif agar hasil yang didapatkan mendekati status refraksi emmetropia (1.0).

Metode yang digunakan adalah metode penelitian deskriptif kuantitatif dengan jumlah populasi sama dengan jumlah sampel sebanyak 30 responden, karena populasi kurang dari 100 responden.

Hasil penelitian, hasil tentatif koreksi mendekati persentase ketepatan $100 \%$ sebesar $65.5 \%$, sedangkan hasil retinoskopi sebesar $58.3 \%$,selisih perbedaan sebesar 7.2\%. Kesimpulannya, Hasil retinoskopist sebesar 58.3\%, hasil tentatif koreksi sebesar $65.5 \%$.
\end{abstract}

Kata Kunci : Scissors Movement, faktor kegagalan pemeriksaan dengan Retinoskopi.

\section{PENDAHULUAN}

Pembangunan kesehatan sebagai bagian integral dari pembangunan nasional pada hakekatnya adalah penyelenggaraan upaya kesehatan untuk mencapai hidup sehat bagi setiap penduduk agar dapat mewujudkan derajat kesehatan yang optimal yang besar artinya bagi pengembangan dan pembinaan sumber daya manusia sebagai modal pembangunan nasional.

Pembinaan yang dilakukan harus sejalan dengan profesi yang disandang oleh seseorang atau suatu organisasi sehingga dalam pelaksanaan pembangunan kesehatan terutama kesehatan mata tidak menimbulkan resiko besar yang akan diderita oleh pasien, hal ini dapat terjadi jika seorang profesi tidak memiliki kemampuan yang memadai terhadap apa yang harus dilakukannya. Bekal ilmu tentang analisa kesehatan umum dan mata, keahlian analisa terhadap suatu kasus kelainan refraksi, peralatan yang memadai, adalah sebahagian penunjang kompetensi yang harus dimiliki atau dikuasai.

Refraksionis optisi/optometris adalah setiap orang yang telah lulus dari pendidikan formal refraksi optisi/optometris sesuai dengan ketentuan peraturan perundangundangan, yaitu berijazah refraksionis optisi/optometris serta telah mendapatkan pengakuan kompetensi yang dibuktikan dengan Surat Tanda Registrasi Refraksionis Optisien/Optometris (STR-RO/STR-O). (Permenkes Nomor 41 Tahun 2015, hal. 5-6).

Beberapa kasus yang peneliti temukan baik berupa pengamatan dan observasi 
secara langsung ataupun tidak langsung pada objek kasus. Diduga bahwa pada saat melakukan koreksi, pemeriksa hanya berpedoman pada hasil autorefraktometer yang diduga proses kalibrasi terhadap alat tersebut jarang dilakukan secara periodik. Hal ini tidak sesuai dengan kompetensi seorang refraksi optisi, dimana seorang refraksi optisi harus dapat memiliki kompetensi untuk dapat melakukan pemeriksaan refraksi subjektif monokular dan menetapkan kelainan refraksi serta jenis terapi yang diperlukan. Koreksi kacamata dengan ukuran penuh sebagaimana tercantum dalam Permenkes nomor 572 tahun 2008 atau diduga tidak sesuai dengan standar pelayanan refraksi optisi tentang pemeriksaan refraksi objektif, untuk mengetahui besarnya koreksi kelainan refraksi tersebut dengan menggunakan autorefraktometer atau streak retinoskopi (Permenkes nomor 41 tahun 2015).

Retinoskopi adalah salah satu alat yang harus dimiliki oleh suatu perusahaan optik sebagai salah satu syarat validitas kelengkapan instrument optik, tapi sangat disayangkan bahwa retinoskopi di optikoptik masih jarang digunakan.

\begin{tabular}{l}
\multicolumn{1}{c}{ Beberapa hasil temuan yang } \\
melatarbelakangi penelitian ini \\
diantaranya :
\end{tabular}

1. Penentuan hasil akhir refraksi berdasarkan pemeriksaan yang terindikasi tidak sesuai dengan prosedur standar untuk tahapan pemeriksaan. Hasil pemeriksaan pemeriksa yang menjadi subjek observasi awal tanpa merujuk visus dasar dalam menentukan power tentatif koreksi.

2. Hasil akhir pemeriksaan berdasarkan penambahan power koreksi pada kacamata lama tanpa mempertimbangkan ada tidaknya kelainan organik atau kelainan astigmat, yang sebenarnya pemeriksaan ini memungkinkan akan lebih mendekati hasil yang lebih akurat jika diawali dengan pengamatan visus dalam penentuan power tentatif koreksi atau autorefraktometer yang terkalibrasi atau retinoskopi.

3. Acuan yang diambil diduga tidak berdasarkan pada tentatif koreksi yang didapatkan dari pengamatan visus, tapi berdasarkan perkiraan penambahan lensa koreksi sampai pasien bisa melihat objek dengan jelas.

Penelitian ini bertujuan untuk Mengetahui persentase ketepatan power refraktif mata hasil pengukuran retinoskopi dan tentatif koreksi terhadap hasil autorefraktometer dan visus pada status refraksi emetropia (1.0). Dilaksanakan pada bulan Juli sampai dengan Agustu 2018

\section{METODE PENELITIAN}

Dalam penelitian ini penulis ingin mengetahui atau mengukur keterkaitan antara persentase ketepatan power refraktif mata yang di hasilkan retinoskopi dengan hasil pengamatan tentatif koreksi terhadap hasil autorefraktometer. Variabel 
penelitian yang akan dikaji dalam penelitian ini dibagi menjadi dua variabel utama, yaitu variabel bebas (A \& X) yang terdiri dua variabel, yaitu hasil pengukuran retinoskopi dan hasil tentatif koreksi (A dan X), Sedangkan variabel terikat (Y) terdiri dari satu variabel, yaitu Persentase ketepatan $(\mathrm{B}=\mathrm{Y})$.

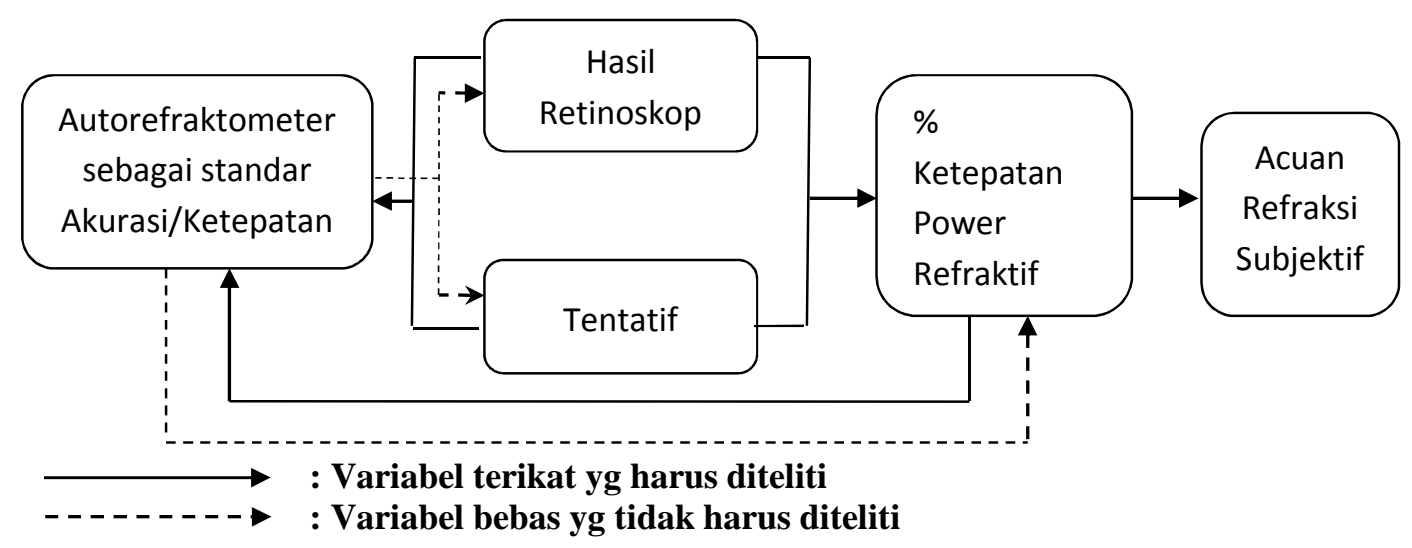

Bagan 1 Kerangka Konsep Penelitian

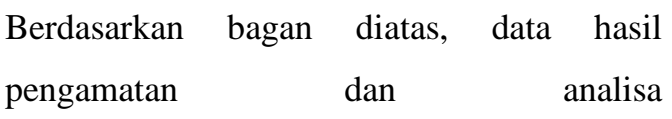
pemeriksa/optisien/ophthometris terhadap power tentatif koreksi dan hasil pengamatan retinoskopi, seberapa dekat ketepatan analisa tersebut jika dilakukan kesesuaian dengan hasil Autorefraktometer sebagai acuan ketepatan.

Jenis penelitian yang dilakukan adalah penelitian observasional dan eksperimental, observasional karena penelitian ini memerlukan langkah-langkah observasi terhadap pasien dan pemeriksa, baik data pribadi ataupun data hasil refraksi sebagai data medical recordnya, eksperimental karena juga dilakukan percobaan penelitian atau pengamatan atas data hasil yang didapatkan dari tentatif koreksi dan data hasil retinoskopi. Penelitian yang dilakukan bersifat deskriptif kuantitatif.
Pendekatan waktu pengumpulan data dengan rancangan yang bersifat Cross Sectional, efek variabel terikat (dependen) dihubungkan dengan variabel bebas (independen) yang dilakukan penilaian kesesuaian variabel sebanyak satu kali saja, tidak dilakukan follow up, dengan arti bahwa semua subjek penelitian tidak dilakukan observasi pada hari atau waktu yang bersamaan, akan tetapi hanya dilakukan penilaian satu kali saja.

Objek yang diteliti sebanyak 30 orang responden atau kurang dari 100 orang responden, maka sampel yang diambil sebanyak total populasi yaitu 30 orang responden. Instrumen yang digunakan dalam penelitian ini adalah lembar observasi yang akan menghasilkan data primer berupa hasil pemeriksaan refraksi baik objektif maupun subjektif dengan metode tentatif koreksi dan retinoskopi didukung autorefraktometer 
sebagai acuan ketepatan dari kedua metode tersebut. Alat yang digunakan dalam penelitian ini adalah trial frame, trial lens, projector chart, retinoskopi, lembar observasi, dan autorefraktometer. Lokasi penelitian di Poli Pediatrik Oftalmologi Rumah Sakit Mata Cicendo Bandung,

Rentang waktu penelitian kurang lebih 2 minggu terhadap 30 orang responden berusia $\geq 8$ tahun s.d $\leq 18$ tahun.

Analisa data yang digunakan adalah analisis univariat berupa analisa data yang bersifat deskriptif kuantitatif. Interpretasi besarnya koefisien ketepatan yang menunjukkan nilai validitas persentase ketepatan yang didapatkan ditunjukkan dalam tabel dibawah ini :

Tabel 1 Interpretasi Nilai Persentase Ketepatan

\begin{tabular}{|c|c|}
\hline $\begin{array}{c}\text { Koefisien Akurasi } \\
(\%)\end{array}$ & Kriteria Akurasi \\
\hline $80.1-100.0$ & Sangat Tinggi \\
\hline $60.1-80.0$ & Tinggi \\
\hline $40.1-60.0$ & Sedang \\
\hline $20.1-40.0$ & Rendah \\
\hline $00.0-20.0$ & Sangat Rendah \\
\hline
\end{tabular}

Sumber : Modifikasi dari tabel hubungan koefisien korelasi Munir, 2007.

\section{HASIL DAN PEMBAHASAN}

Responden adalah pasien dari Rumah Sakit Mata Cicendo dengan rentang usia antara 8 tahun s.d $\leq 18$ tahun yang melakukan pemeriksaan mata baik pasien lama yang melakukan kontrol kesehatan mata ataupun pasien baru yang mengalami gangguan penglihatan berupa kelainan refraksi baik miopia, hipermetropia atau astigmatisma tanpa dibarengi adanya gangguan kelainan organik ataupun gangguan kesehatan mata yang berat akibat glaukoma, katarak ataupun akibat diabetes melitus.

Bbeberapa faktor yang dapat mempengaruhi hasil penelitian terutama pada persentase hasil pemeriksaan yang dilakukan dengan menggunakan retinoskopi atau hasil tentatif koreksi, diantaranya human Error (Pemeriksa ataupun responden), parameter ruang pemeriksaan (seperti pencahayaan) (tidak dibahas), parameter Instrumen yang digunakan (seperti retinoskopi, trial frame, trial lens ataupun proyektor chart yang kurang kontras), kondisi kesehatan mata (seperti refleks retina/diameter pupil yang normal, ataupun terdapat refraktif error).

Retinoskopi memungkinkan kita mengukur status refraksi tidak harus bergantung pada responden secara aktif atau tanpa adanya interaksi secara verbal, teknik pemeriksaan dengan menggunakan retinoskopi memungkinkan mendapatkan hasil yang akurat, dapat dipercaya dan dapat dipertanggungjawabkan, dimana pada saat pemeriksaan subjektif tidak dapat dilakukan terutama pada beberapa responden yang kurang kooperatif ataupun yang memiliki kelainan organik yang berat sehingga hasil pengukuran meragukan, tapi metode pemeriksaan dengan retinoskopi akan sangat memuaskan dan akurasi yang tinggi untuk determinasi objek sangat bermanfaat bila dilakukan dengan diameter pupil yang 
sesuai dengan media yang jernih. Namun demikian untuk mendapatkan hasil dengan akurasi tinggi, diperlukan keterampilan yang tinggi, diasah setiap saat, analisa yang bagus dari seorang pemeriksa, Instrumen yang baik (retinsokopi, trial frame, trial lensa).

Beberapa hal yang membuat hasil retinoskopi tidak akurat, yaitu :

1. Kesalahan Jarak Kerja

Kesalahan dalam jarak kerja akan menyebabkan kesalahan yang signifikan terhadap hasil pengukuran, jika pemeriksa bekerja dengan jarak yang sangat dekat akan didapatkan suatu kesalahan dimana didapatkan power plus yang terlalu besar atau power minus yang terlalu kecil, sedangkan bila jarak kerja yang terlalu jauh akan didapatkan hasil yang sebaliknya.

2. Keluar dari jangkauan aksis visual responden

Selama pemeriksa masih bekerja dalam 2 atau 3 derajat dari aksis visual pasien, tidak akan didapatkan kesalahan yang sangat signifikan.

3. Kegagalan dari pasien untuk memfiksasi target(hal ini tergantung dari komunikasi pemeriksa dengan responden).

4. Kadang-kadang responden (biasanya anak-anak), akan memfiksasi dan berakomodasi pada sumber yang lebih dekat dari target jauh, menyebabkan kelainan refraksi yang ditemukan sebesar 1.00DS sampai dengan 2.00DS lebih besar dari kelainan miopia dan lebih kecil dari kelainan hypermetropia.
5. Kegagalan untuk menemukan principal meridian.

6. Kegagalan untuk mengenali scissors movement

Jadi pada saat pemeriksaan retinoskopi dengan kondisi pupil kecil, akan terjadi aberasi spherical dan dapat muncul scissors movement (paling umum kasus yang terjadi ini dikendalikan dengan penggunaan sikloplegik).

\section{Aberasi pada refleks retinoskopi :}

Pada astigmat irreguler hampir selalu tampak aberasi pada refleks. Aberasi Spherical cenderung meningkatkan cahaya yang masuk ke sentral dan perifer pupil, tergantung aberasi yang terjadi positif atau negatif. Pada suatu titik netralisasi, satu bagian dapat mengalami miopia dan bagian yang lain mengalami hypermetropia sehingga didapatkan suatu hasil pengamatan yang disebut "Scissors Refleks" atau scissors movement. Kadang-kadang pada suatu astigmat irreguler yang berat atau adanya kekeruhan optikal akan membingungkan pemeriksa. Hal ini terjadi karena adanya distorsi dari bayangan yang akan mengurangi hasil retinoskopi, dan pada kasus seperti ini sebaiknya dikonfirmasi dengan pemeriksaan subjektif. (Malyanti N Akib, MD ; 42 $2^{\text {nd }}$ Annual Scientific Meeting of Indonesian Ophtalmologist Associatons, 27-29 September 2017, Hal. 93-101). 
Dengan berlandaskan pada 6 point diatas hal inilah yang terjadi pada saat penelitian dengan menggunakan retinoskopi, sehingga hasil yang didapatkan dari pemeriksaan tersebut menunjukkan bahwa nilai persentase ketepatan refraktif mata hasil retinsokopi lebih kecil dibandingkan dengan hasil tentatif koreksi berdasarkan pengamatan visus status refraksi emmetropia (1.0) terhadap hasil autorefraktometer.

\section{Faktor-faktor Yang Mempengaruhi Distribusi Kelainan Refraksi}

Faktor-faktor yang dapat mempengaruhi distribusi kelainan refraksi yang dialami oleh responden yang mungkin juga berpengaruh terhadap pelaksanaan penelitian pemeriksaan refraktif mata baik yang dilakukan dengan retinoskopi ataupun yang dilakukan dengan pengamatan pada power tentatif koreksi, sehingga mempengaruhi hasil yang didapatkan dalam penelitian.

Tabel 2. Faktor-faktor Yang Mempengaruhi Kelainan refraksi

TABLE 2-3 Astigmatism in Infancy and Toddlerhood

\begin{tabular}{|c|c|c|c|c|c|}
\hline Author & $N$ & $\begin{array}{c}\text { Cycloplegic } \\
\text { Agent/Method }\end{array}$ & Age & $\begin{array}{c}\text { Prevalence of } \\
\text { Astigmatism }\end{array}$ & Orientation \\
\hline $\begin{array}{l}\text { Ingram \& } \\
\text { Barr }^{34}\end{array}$ & 296 eyes & Atropine/retinoscopy & $\begin{array}{l}1 \mathrm{yr} \\
3.5 \mathrm{yr}\end{array}$ & $\begin{array}{r}29.7 \%(>1.00 \mathrm{DC}) \\
7.8 \%(>1.00 \mathrm{DC})\end{array}$ & $\begin{array}{l}\text { Not given } \\
\text { Not given }\end{array}$ \\
\hline Fulton $\mathrm{et}^{\text {al. }}{ }^{30}$ & 145 children & $\begin{array}{l}\text { Cyclopentolate } 1 \% / \\
\text { retinoscopy }\end{array}$ & $\begin{array}{l}40-50 \mathrm{wk} \\
1-2 \mathrm{yr} \\
2-3 \mathrm{yr}\end{array}$ & $\begin{array}{l}23.5 \%(\geq 21.00 \mathrm{DC}) \\
16 \%(\geq 1.00 \mathrm{DC}) \\
14 \%(\geq 1.00 \mathrm{DC})\end{array}$ & $\begin{array}{l}71 \% \text { ATR } \\
\text { (for children } \\
0-3 \text { yr } \\
21 \% \text { WTR } \\
8 \% \text { Oblique }\end{array}$ \\
\hline Dobson et al. ${ }^{29}$ & $\begin{array}{r}46 \text { infants } \\
187 \text { infants }\end{array}$ & $\begin{array}{l}\text { Cyclopentolate } 1 \% / \\
\text { retinoscopy }\end{array}$ & $\begin{array}{l}<6 \mathrm{mo} \\
1 \mathrm{yr} \\
\quad \text { (midpoint) }\end{array}$ & $\begin{array}{l}17 \%(\geq 1.00 \mathrm{DC}) \\
19 \%(\geq 1.00 \mathrm{DC})\end{array}$ & $\begin{array}{l}100 \% \text { ATR } \\
70 \% \text { ATR } \\
18 \% \text { ATR } \\
2 \% \text { Oblique }\end{array}$ \\
\hline Howland et al." & 93 infants & $\begin{array}{l}\text { No cycloplegia/ } \\
\text { photorefraction }\end{array}$ & $0-12 \mathrm{mo}$ & $86 \% \geq 1.00 \mathrm{DC}$ & $\begin{array}{c}70 \% \text { "Horizontal } \\
\text { and vertical" }\end{array}$ \\
\hline Gwiazda et al." & 521 infants & $\begin{array}{l}\text { No cycloplegia/ } \\
\text { near retinoscopy }\end{array}$ & $0-12 \mathrm{mo}$ & $53 \% \geq 1.00 \mathrm{DC}$ & $\begin{array}{l}41 \% \text { ATR } \\
41 \% \text { WTR } \\
18 \% \text { Oblique }\end{array}$ \\
\hline $\begin{array}{l}\text { Howland \& } \\
\text { Sayles }^{32}\end{array}$ & 117 infants & $\begin{array}{l}\text { No cycloplegia/ } \\
\text { photorefraction }\end{array}$ & $0-12 \mathrm{mo}$ & $63 \%$ & $\begin{array}{l}55 \% \text { ATR } \\
3 \% \text { WTR } \\
42 \% \text { Oblique }\end{array}$ \\
\hline Mohindra et al. ${ }^{35}$ & 276 infants & $\begin{array}{l}\text { No cycloplegia/near } \\
\text { retinoscopy }\end{array}$ & $0-12 \mathrm{mo}$ & $45 \%$ & $\begin{array}{l}40 \% \text { ATR } \\
40 \% \text { WTR } \\
20 \% \text { Oblique }\end{array}$ \\
\hline Santonastaso ${ }^{28}$ & $\begin{array}{l}34 \text { infants under } \\
3 \text { mo of age }\end{array}$ & $\begin{array}{l}\text { Atropine/ } \\
\text { retinoscopy }\end{array}$ & $0-12 \mathrm{mo}$ & $52.4 \% \geq 1.00 \mathrm{DC}$ & $\begin{array}{l}15 \% \text { ATR } \\
85 \% \text { WTR }\end{array}$ \\
\hline Ehrlich et al. ${ }^{36}$ & 254 infants & $\begin{array}{l}\text { Cyclopentolate } 1 \% / \\
\text { retinoscopy }\end{array}$ & $9 \mathrm{mo}$ & $35 \% \geq 1.00 \mathrm{DC}$ & $\begin{array}{l}17 \% \text { ATR } \\
81 \% \text { WTR }\end{array}$ \\
\hline & & & $20 \mathrm{mo}$ & $13 \% \geq 1.00 \mathrm{DC}$ & $\begin{array}{l}36 \% \text { ATR } \\
58 \% \text { WTR }\end{array}$ \\
\hline Mayer et al. ${ }^{\prime}$ & $\begin{array}{l}43 \text { infants } \\
33 \text { infants }\end{array}$ & $\begin{array}{l}\text { Cyclopentolate } 1 \% / \\
\text { retinoscopy }\end{array}$ & $\begin{array}{l}4 \mathrm{mo} \\
48 \mathrm{mo}\end{array}$ & $\begin{array}{l}49 \% \geq 1.00 \mathrm{DC} \\
12 \% \geq 1.00 \mathrm{DC}\end{array}$ & $\begin{array}{l}56 \% \text { ATR } \\
29 \% \text { WTR } \\
\text { across age } \\
\text { groups }\end{array}$ \\
\hline Mutti et al. ${ }^{2}$ & 262 infants & $\begin{array}{l}\text { Cyclopentolate } 1 \% / \\
\text { retinoscopy }\end{array}$ & $3 \mathrm{mo}$ & $42 \% \geq 1.00 \mathrm{DC}$ & $\begin{array}{l}6 \% \text { ATR } \\
89 \% \text { WTR }\end{array}$ \\
\hline & & & $36 \mathrm{mo}$ & $4 \% \geq 1.00 \mathrm{DC}$ & $\begin{array}{l}78 \% \text { ATR } \\
22 \% \text { WIR }\end{array}$ \\
\hline
\end{tabular}

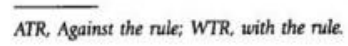

Sumber :Benjamin, Borish's Clinical Refractions ; Incidence and Distribution of Refractive Anomalies Chapter Z 37-38 
Tabel 3. Effect Of Myopia Criterion Definitions On Prevalensi of Myiopia In School Age Children

\begin{tabular}{|c|c|c|}
\hline \multirow{2}{*}{ Usia (Tahun) } & \multicolumn{2}{|c|}{ Myopia } \\
\cline { 2 - 3 } & $\mathbf{- 0 . 1 2}$ D atau Lebih & $\mathbf{- 1 . 0 0}$ D atau Lebih \\
\hline$<5$ s.d 6 & $6.8 \%$ & $0.6 \%$ \\
\hline $7-8$ & $10.4 \%$ & $1.0 \%$ \\
\hline $9-10$ & $16.7 \%$ & $2.0 \%$ \\
\hline $11-12$ & $21.2 \%$ & $4.5 \%$ \\
\hline $13-14$ & $24 \%$ & $5.4 \%$ \\
\hline
\end{tabular}

Sumber : Benjamin, Borish's Clinical Refractions

\section{SIMPULAN}

1. Persentase ketepatan power refraktif mata yang didapatkan dari pemeriksaan mata terhadap responden yang dilakukan dengan menggunakan retinoskopi hasil pengamatan peneliti dan retinoskopist sebesar $58.3 \%$, dan persentase ketepatan hasil retinoskopi berdasarkan spherical equivalen sebesar $40.7 \%$.

2. Persentase ketepatan power refraktif mata yang didapatkan dari pemeriksaan yang dilakukan berdasarkan metode tentatif koreksi sebesar 65.5\%, dan persentase ketepatan hasil tentatif koreksi berdasarkan spherical equivalen sebesar 71.2\%.

3. Persentase perbandingan hasil pengamatan power refraktif mata yang dihasilkan antara hasil pengamatan retinoskopi dengan tentatif koreksi, didapatkan nilai ketepatan sebesar $58.3 \%: 65.5 \%$ terhadap hasil autorefraktometer yang terkalibrasi dan perbandingan Spheris Equivalen yang terjadi pada hasil retinoskopi dengan tentatif koreksi sebesar $40.7 \%$ : 71.2 $\%$ dengan selisih $7.2 \%$ dan $\mathrm{SE}=$ $30.5 \%$.

\section{SARAN}

1. Berdasarkan hasil penelitian, bahwa tentatif koreksi yang dilakukan sesuai prosedur tahapan refraksi dapat mencapai hasil persentase ketepatan mendekati $100 \%$, Maka dari itu, kompetensi setiap optisien/opthometris harus terus dilatih dengan tetap berpedoman pada tahapan pemeriksaan kelainan refraksi yang telah ditentukan didalam standar operasional prosedur.

2. Penggunaan retinoskopi disarankan untuk terus digunakan dalam setiap pemeriksaan refraksi objektif manakala sebuah optik belum memiliki autorefraktometer, retinoskopi memiliki kelebihan yang praktis dan dapat digunakan pada responden yang kurang kooperatif, hasil yang lebih 
akurat jika retinoskopi dipelajari dan digunakan secara regular, dapat meningkatkan analisa setiap optisien/opthometris terhadap penentuan kelainan refraksi yang diderita oleh responden

\section{DAFTAR PUSTAKA}

American Academy of Optometry, 2006. AOA, Clinical Optics, CHAPTER 3: Optics of the Human Eye. 107

Butterworth-Heinnemann, 2007, Benjamin W, 2008. Bor Cearical Refraction, Elliott D B. Clinical procedures in primary eye care 3/e. Oxford, Elsevier, 2008;

Butterworth, Heinemann1997; EskridgeJB, AmosJF, BartlettJD, Clinical Procedures in Optometry, Philadelphia, PA:

J.B.LippincottCompany, 1991

Benjamin, Borish's Clinical Refractions ; Hal. 37-38 Reprinted with permission from Myopia : Prevalensi and progression. Copyright 1989 by the Nasional Academy Of Sciences Courtesy of The National Academy Press. Washington D.C.

Borish's Clinical Refractions, 1984 :

Tabel Bennet \& Rabbetts

Brien Holden Vision Institute ; Clinical Optometric Procedures, Objective Reractions 1, Hal.12.

$\begin{array}{cl}\text { Badan Standar } & \text { Nasional } \\ \text { Pendididkan. } & \text { (2006). Model } \\ \text { Penilaian } & \text { Kelas. Jakarta: }\end{array}$

BSNP, download : 10-02-2018

Carlson N Band Kurtz D. Clinical procedures for ocular examination.3/e. Mac Graw-Hill Companies, Inc. United States. 2004

Courtesy of Neal H, Arebara, MD. Redrawn oleh C. H. Wooley, Clinical Optics, AOA ; CHAPTER 3: Optics of the Human Eye. 105
Ettinger E R dan Rouse M W., Clinical Decision Making in Optometry, 1/e, Butterworth, Heinemann 1997; Eskridge J B, Amos J F, Bartlett J D, Clinical Procedures in Optometry, Philadelphia, PA: J.B. Lippincott Company, 1991.

Eskridge JB, Amos JF, Bartlett JD, Prosedur Klinis di Optometri, Philadelphia, PA: J.B.Lippincott Company, 1991. Benjamin W, Refraksi Klinis Borish, ButterworthHeinemann, 2007), (Pirindhavellie Govender: Universitas KwaZulu Natal (UKZN) Durban, Afrika Selatan, Bina Patel: New England College of Optometry, Amerika Serikat.

ElliottDB.Clinical procedures in primary eye care3/e.Oxford, Elsevier, 2008;

EttingerER dan RouseMW., Clinical Decision Making in Optometry, 1/e,

Malyanti N Akib, MD ; 42 ${ }^{\text {nd }}$ Annual Scientific Meeting Of Indonesian Ophtalmologist Associatons, 27-29 September 2017, Hal. 93-101

Nana Sudjana.Penilaian Hasil Proses Belajar Mengajar. (Bandung: PT. Remaja Rosdakarya, 1995). hal: 24.Edited with the trial version of Foxit Advanced PDF Editor To remove this notice, visit: www. foxitsoftware.com/shopping, do wnload : 10-02-2018.

Nana Sudjana, Dasar-dasar Proses Belajar Mengajar, (Bandung: Sinar Baru Algensindo, 2013) hlm 5Sukiman, Pengembangan Sistem Evaluasi, (Yogyakarta: Insan Madani), hlm. 57; Wowo Sunaryo Kuswana, Taksonomi Kognitif, (Bandung: PT Remaja Rosdakarya, 2012), hlm 44, download 10-022018. 
Prof.Dr. Soekidjo Notoatmodjo ; Metodologi Penelitian Kesehatan, 202-203 ; Edisi Revisi-Jakarta : Rineka Cipta, 2014).

Presisi Akurasi PDF - Bab Besaran dan Satuan http://atophysics.wordpress.com; Nurulnhi Hidayahon Oct 06, 2012, Hal.11, download 29-01-2018

Permenkes Nomor 572/MenKes/SK/VI/2008, hal. 5-6.

Permenkes Nomor 41 Tahun 2015, hal. 5-6.

Shih-Yen Ee, Koh A, Tan D. Intervensi untuk menghambat perkembangan miopia pada anak-anak: sebuah update berbasis bukti
Ophthalmology. 2002; 109 (3): 415421.

Salik Hawarij \& Hasna Afifah, Medicinesia; Refraksi cahaya pada mata; 17 Januari 2013, download 0702-2018.

Skuta et al, 2011; Khurana AK et al, 2007; Lang GK, 2000. Skuta et al, 2011; Khurana AK et al, 2007; Leitman MW, 2007. Skuta et al, 2011; Khurana AK et al,2007; Olver J et al,2005. http://optometryzone.com/2016/11/ $10 /$ working-distance-lens www.medicalgainer.com/2017/07/r etinoscopy-Principle-ProcedureInferences.html 